\title{
Functional Organization of Presynaptic Metabotropic Glutamate Receptors in Vagal Brainstem Circuits
}

\author{
Kirsteen N. Browning and R. Alberto Travagli \\ Department of Neuroscience, Pennington Biomedical Research Center, Louisiana State University System, Baton Rouge, Louisiana 70808
}

\begin{abstract}
We demonstrated previously that, by suppressing cAMP levels, metabotropic glutamate receptors (mGluRs) play a crucial role in opioid receptor trafficking on GABAergic nerve terminals within gastric brainstem vagal circuits. Using whole-cell patch-clamp recordings, we aimed to correlate the influence of sensory vagal afferent fibers with the functional organization of mGluRs on the synaptic connections between the nucleus tractus solitarius and dorsal motor nucleus of the vagus. Group II mGluRs were identified on both excitatory and inhibitory synapses; the receptor-selective agonist APDC [(2R,4R)-4-aminopyrrolidine-2,4-dicarboxylate] induced a concentrationdependent decrease in glutamatergic and GABAergic synaptic transmission $\left(\mathrm{EC}_{50}, \sim 20 \mu \mathrm{m}\right.$ for both). The group II mGluRs were activated tonically on GABAergic, but not glutamatergic synapses, as the receptor-selective antagonist (2S)- $\alpha$-ethylglutamic acid (EGLU; $200 \mu \mathrm{M}$ ) modulated GABA currents only. After selective vagal deafferentation, EGLU was without effect, suggesting that vagal afferent (sensory) fibers are the source of this tonic input. Conversely, group III mGluRs, although not activated tonically, were present on excitatory, but not inhibitory, synapses; in fact, the receptor-selective agonist L-AP-4 [L-(+)-2-amino-4-phosphonbutyric acid] induced a concentration-dependent decrease in glutamatergic synaptic transmission $\left(\mathrm{EC}_{50}, \sim 2 \mu \mathrm{M}\right)$ but had no effect on GABAergic synaptic transmission. Together with our previous results on receptor trafficking, these data suggest that visceral information plays a fundamental role in shaping the response of homeostatic brainstem circuits that receive inputs from higher integrative neuronal centers.
\end{abstract}

Key words: autonomic; brainstem; dorsal motor nucleus; patch clamp; solitary; solitarius; vagus

\section{Introduction}

Body homeostasis is determined by the fine interplay of many factors, including the influence that higher CNS centers play on the visceral reflexive activity occurring in the brainstem (Berthoud, 2007). These circuits must undergo extensive plasticity that permits adaptation to ever-changing external and internal factors, such as the feeding status. Visceral sensory information is conveyed to the CNS via vagal afferent nerve fibers terminating within the nucleus tractus solitarius (NTS). Neurons of the NTS integrate this information with that received from and sent to other CNS centers modulating homeostatic and visceral reflexes, including the adjacent dorsal motor nucleus of the vagus (DMV) (Andresen and Kunze, 1994; Jean, 2001; Travagli et al., 2006). With respect to gastrointestinal vagal reflexes, DMV neurons receive glutamatergic, catecholaminergic, or, principally, GABAergic inputs from the NTS (Travagli et al., 1991; Willis et al., 1996; Sivarao et al., 1998; Rogers et al., 2003; Davis et al., 2004).

Vagal afferent fibers use glutamate as their principal neurotransmitter and fast synaptic transmission via ionotropic receptors is critically important in sensory integration (Andresen and

\footnotetext{
Received March 12, 2007; revised May 17, 2007; accepted June 15, 2007.

This work was supported by National Institutes of Health Grant DK55530. We thank Cesare M. Travagli and W. Nairn Browning for support and encouragement.

Correspondence should be addressed to Dr. R. Alberto Travagli, Department of Neuroscience, Pennington Biomedical Research Center, Louisiana State University System, Baton Rouge, LA 70808. E-mail: alberto.travagli@pbrc.edu.

DOI:10.1523/JNEUROSCI.1105-07.2007

Copyright $\odot 2007$ Society for Neuroscience $\quad$ 0270-6474/07/278979-10\$15.00/0
}

Yang, 1990; Hornby, 2001; Baptista et al., 2005). Metabotropic glutamate receptors (mGluRs) are also present on vagal neurons and nerve fibers (Hay et al., 1999; Hoang and Hay, 2001; Pamidimukkala et al., 2002). Whereas group I mGluRs are commonly found at postsynaptic locations, groups II and III mGluRs are generally located presynaptically where they act as autoreceptors, decreasing synaptic transmission as a consequence of adenylate cyclase inhibition (Conn and Pin, 1997; Cartmell and Schoepp, 2000). Electrophysiological studies have demonstrated that group II and III mGluRs modulate the excitability of vagal afferent neurons and nerve fibers, and modulate synaptic transmission to NTS neurons (Glaum and Miller, 1993b; Hoang and Hay, 2001; Chen et al., 2002; Jin et al., 2004; Chen and Bonham, 2005).

Our previous studies illustrated the potential role of mGluRs in the control of inhibitory neurotransmission modulation (Browning et al., 2006). Normally, the low resting cAMP levels of inhibitory nerve terminals prevents the modulation of GABA synaptic transmission by several neuromodulators such as opioid peptides. Elevating cAMP levels induces trafficking of $\mu$-opioid receptors to the nerve terminal membrane where their interaction with endogenous opioids inhibits GABAergic synaptic transmission (Browning et al., 2004, 2006; Browning and Travagli, 2006). Previously, we demonstrated that cAMP levels within these nerve terminals are low because of tonic activation of group II mGluRs (Browning et al., 2006).

In contrast, glutamatergic NTS-DMV synaptic transmission within gastric brainstem circuits is open to inhibition by a variety of neuromodulators (Bertolino et al., 1997b; Browning and 
Travagli, 2003; Derbenev et al., 2004; Williams et al., 2006), suggesting that excitatory nerve terminals have higher cAMP levels. Such distinctions suggest differences in the organization of glutamatergic and GABAergic synapses. Indeed, we hypothesized that that these differences are caused by either a different distribution of mGluRs on excitatory and inhibitory synapses or by differences in the organization of monosynaptic connections made by vagal afferent nerve fibers (Browning et al., 2006).

The aim of this study, therefore, was to investigate, using electrophysiological tools, the functional organization of mGluRs on excitatory versus inhibitory nerve terminals within NTS-DMV gastric brainstem circuits.

\section{Materials and Methods}

All animal procedures reported in the present study were approved by the Pennington Biomedical Research Center-Louisiana State University System Institutional Animal Care and Use Committee and conform fully with the National Institutes of Health guidelines.

Retrograde tracing. Gastric-projecting DMV neurons were labeled by application of the retrograde neuronal tracer $1,1^{\prime}$-dioctadecyl-3,3,3',3'tetramethylindocarbocyanine perchlorate $\left[\mathrm{DiIC}_{18}(\mathrm{DiI})\right]$ to discrete regions of the stomach as described previously (Browning et al., 1999, 2002, 2004). Briefly, after induction of anesthesia (isoflurane, $2.5 \%$ with air, $600 \mathrm{ml} / \mathrm{min}$; abolition of the foot pinch withdrawal reflex), the abdominal areas of 14-d-old rat pups of either sex were cleaned with Novalsan and alcohol before performing a laparotomy. The stomachs were isolated from surrounding tissues and crystals of DiI were apposed to the surface of one gastric region per rat, either the greater curvature of the fundus or corpus, or to the antrum/pylorus (A/P). The dye was embedded in place using a fast-hardening epoxy resin before the entire surgical area was washed with warm sterile saline. The abdomen was closed with 5/0 silk suture and the rat allowed to recover for 10-15 d before experimentation.

Electrophysiological recording. Electrophysiological recordings were made from rat brainstem slices prepared as described previously (Browning et al., 1999). Rats were anesthetized with isoflurane before administration of a bilateral pneumothorax. The brainstem was removed and placed in chilled, oxygenated Krebs' solution (for composition, see below). Four to six coronal slices containing the dorsal vagal complex (DVC) were cut (300 $\mu \mathrm{m}$ thick) using a vibratome. Slices were incubated in Krebs' solution at $35^{\circ} \mathrm{C}$ for at least 90 min before recording. A single slice was transferred to a custom-made perfusion chamber (volume, 500 $\mu \mathrm{l}$; Michigan Precision Instruments, Parma, MI) and kept in place with a nylon mesh. Slices were maintained at $35^{\circ} \mathrm{C}$ by perfusion with warmed Krebs' solution at a rate of $2.5-3.0 \mathrm{ml} / \mathrm{min}$. Gastric-projecting neurons (DiI-filled) were identified using a Nikon (Tokyo, Japan) E600FN microscope equipped with tetramethylrhodamine isothiocyanate epifluorescent filters. Once the identity of a DiI-filled neuron was confirmed, electrophysiological recordings were made under bright-field illumination using Nomarski optics.

Whole-cell recordings were made with patch pipettes of resistance $2-5$ $\mathrm{M} \Omega$ when filled with K-gluconate intracellular solution (see below). Data were acquired using a single electrode voltage-clamp amplifier (Axopatch 1D; Molecular Devices, Sunnyvale, CA) at a rate of $10 \mathrm{kHz}$, filtered at $2 \mathrm{kHz}$, and digitized via a Digidata 1320 interface (Molecular Devices) before being stored and analyzed on a personal computer using pClamp9 software (Molecular Devices) or Mini Analysis software (Jaejin Software, Leonia, NJ). Only recordings with a series resistance $<15 \mathrm{M} \Omega$ were considered acceptable.

Drugs were applied via perfusion through a series of manually operated valves at concentrations demonstrated previously to be effective (Chen et al., 2002; Jin et al., 2004; Browning et al., 2006). Agonists were applied for periods of time sufficient for the response to reach plateau, and neurons were allowed to recover fully between drug additions. Antagonists were perfused for at least $5 \mathrm{~min}$ before assessment of their effects. Each neuron served as its own control (i.e., the response was assessed before, during, and after drug addition using ANOVA with repeated measures). The $\chi^{2}$ test was used to compare results of different treatments in different groups of animals. Statistical significance was set at $5 \%$. A minimum $\pm 10 \%$ variation of the amplitude of evoked currents was arbitrarily taken as indicative of an effect. Results are expressed as mean \pm SEM. Only responding neurons were included in the statistical analysis.

Electrical stimulation. Tungsten bipolar stimulating electrodes (tip size, 1-5 $\mu \mathrm{m}$; electrode tip separation, $\sim 125 \mu \mathrm{m}$; WPI, Sarasota, FL) placed in the centralis (cNTS) or medialis (mNTS) subnuclei of the NTS were used to evoke synaptic currents in the recorded DMV neuron. No noticeable differences in the synaptic responses in DMV neurons were observed when stimulating cNTS or mNTS, the data were thus pooled. Pairs of stimuli (0.05-1.0 ms, $10-500 \mu \mathrm{A}, 35-400 \mathrm{~ms}$ apart) were applied every 20 or $60 \mathrm{~s}$, respectively, to evoke either submaximal EPSCs or IPSCs. When recording EPSCs, the perfusing Krebs' solution contained $50 \mu \mathrm{M}$ picrotoxin to prevent GABAergic currents. When recordings IPSCs, the perfusing Krebs' solution contained $1 \mathrm{~mm}$ kynurenic acid to prevent glutamatergic ionotropic currents. The recording pipette solution contained lidocaine $N$-ethyl bromide $(0.5 \mu \mathrm{M})$ to prevent antidromically activated action potentials. When recording miniature IPSCs, the intracellular solution contained $\mathrm{KCl}$ rather than $\mathrm{K}$-gluconate, and the perfusing solution contained tetrodotoxin (TTX; $1 \mu \mathrm{M}$ ) to block action potential dependent synaptic transmission. Recordings were conducted at either $-50 \mathrm{mV}$ (IPSCs) or $-60 \mathrm{mV}$ (EPSCs).

Vagal deafferentation. A unilateral vagal nerve deafferentation was performed in 25 rats as described previously (Browning et al., 2006; Baptista et al., 2007). Briefly, rats were anesthetized with a mixture of ketamine/ acepromazine/xylazine in saline $(80 \mathrm{mg} / 1.6 \mathrm{mg} / 5 \mathrm{mg} / \mathrm{ml}$ respectively, 0.1 $\mathrm{ml} / 100 \mathrm{~g}$ of body weight). After a deep level of anesthesia was obtained (abolition of the foot-pinch withdrawal reflex), rats were placed in a stereotaxic frame (Kopf Instruments, Tujunga, CA). A dorsolateral incision was made at the level of the occipital bone and the muscle tissue blunt dissected to expose the cervical vertebrae and the occipital bone. After "shaving" the occipital bone, all three supranodose vagal dorsal afferent rootlets on one vagal trunk were sectioned under microscopic guidance using a 27 gauge needle. The incision was closed with 5/0 silk suture and the rats allowed to recover for $4-5 \mathrm{~d}$ before experimentation. Hereafter, these rats will be referred to as "deafferented." Although we realize that in cutting the brainstem slices to perform electrophysiological recordings implies that the vagus nerve trunks are also sectioned, we refer to these rats as "vagally intact" because vagal afferent fibers are still viable in the slice preparation.

Solution composition. Krebs' solution contained (in mM) $126 \mathrm{NaCl}, 25$ $\mathrm{NaHCO}_{3}, 2.5 \mathrm{KCl}, 1.2 \mathrm{MgCl}_{2}, 2.4 \mathrm{CaCl}_{2}, 1.2 \mathrm{NaH}_{2} \mathrm{PO}_{4}$, and 11 dextrose, maintained at $\mathrm{pH} 7.4$ by bubbling with $95 \% \mathrm{O}_{2}-5 \% \mathrm{CO}_{2}$. Intracellular potassium gluconate solution contained (in $\mathrm{mM}$ ) $128 \mathrm{~K}$-gluconate, 10 $\mathrm{KCl}, 0.3 \mathrm{CaCl}_{2}, 1 \mathrm{MgCl}_{2}, 10$ HEPES, 1 EGTA, 2 ATP-Na, and 0.25 GTP$\mathrm{Na}$, adjusted to $\mathrm{pH} 7.35$ with $\mathrm{KOH}$. Intracellular potassium chloride solution contained (in mM) $140 \mathrm{KCl}, 1 \mathrm{CaCl}_{2}, 1 \mathrm{MgCl}_{2}, 10 \mathrm{HEPES}, 10$ EGTA, 2 ATP-Na, and 0.25 GTP-Na, adjusted to pH 7.35 with $\mathrm{HCl}$.

Drugs and chemicals. DiI was purchased from Invitrogen (Eugene, OR). L-(+)-2-Amino-4-phosphonobutyric acid (L-AP-4), $(2 R, 4 R)-4$ aminopyrrolidine-2,4-dicarboxylate (APDC), (2S)- $\alpha$-ethylglutamic acid (EGLU), and (RS)- $\alpha$-methylserine-O-phosphate (MSOP) were purchased from Tocris (Ellisville, MO). Unless specified previously, all other chemicals were purchased from Sigma (St. Louis, MO), except for TTX, which was purchased from Alomone Labs (Jerusalem, Israel).

\section{Results}

Whole-cell patch-clamp recordings were made from a total of 171 gastric-projecting DMV neurons from 65 rats. Of these, 110 neurons (34 fundus-, 29 corpus-, and $47 \mathrm{~A} / \mathrm{P}$-projecting) were from 43 "vagally intact" rats (13 fundus-, 13 corpus-, and 17 A/P-labeled), whereas the remaining 61 neurons ( 9 fundus-, 25 corpus-, and $27 \mathrm{~A} / \mathrm{P}$-projecting) were from 22 "deafferented" rats (4 fundus-, 8 corpus-, and 10 A/P-labeled). The effects of metabotropic mGluR-selective agonists and antagonists were qualitatively and quantitatively similar between different gastricprojecting neurons; the results were therefore pooled. 

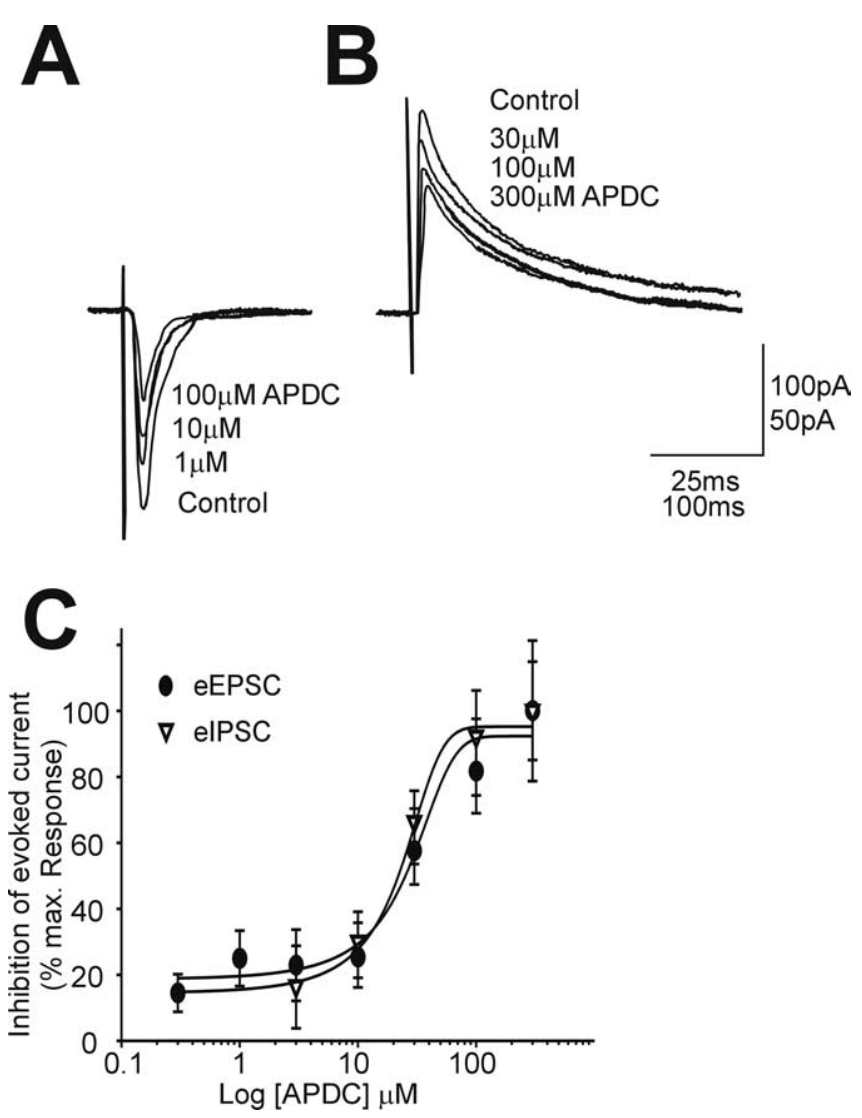

Figure 1. The group II mGluRagonist inhibits excitatory and inhibitory synaptic transmission to gastric-projecting DMV neurons. $A$, In a gastric-projecting DMV neuron voltage clamped at $-60 \mathrm{mV}$, eEPSCS were evoked by electrical stimulation of the adjacent NTS. The group II mGluR agonist APDC induced a concentration-dependent inhibition in the amplitude of eEPSCs. Calibration: $25 \mathrm{~ms}, 100 \mathrm{pA} . \boldsymbol{B}$, In a different gastric-projecting DMV neuron voltage clamped at -50 $\mathrm{mV}$, elPSCs were evoked by electrical stimulation of the adjacent NTS. The group II mGluR agonist APDC induced a concentration-dependent inhibition in amplitude of elPSCs. Calibration: 100 ms, 50 pA. C, Log concentration-response curve illustrating the APDC-induced inhibition in eEPSC and elPSC amplitude. Note that the estimated $\mathrm{EC}_{50}$ is $\sim 20 \mu \mathrm{m}$ for both.

\section{Activation of presynaptic group II mGluRs inhibits excitatory} synaptic transmission to gastric-projecting DMV neurons

The effects of the group II mGluR agonist APDC were tested on 32 gastric projecting, vagally intact DMV neurons. In the presence of picrotoxin, APDC $(100 \mu \mathrm{M})$ induced a $35 \pm 6.7 \mathrm{pA}$ outward shift in the holding current in 12 of these neurons $(37.5 \%)$. Neither the proportion of neurons responding to APDC with an outward current (three of six neurons; $50 \% ; p>0.05$ vs proportion of neurons responding under control conditions), nor the magnitude of this APDC-induced outward current was altered by perfusion with TTX $(1 \mu \mathrm{M} ; 29 \pm 12.8 \mathrm{pA} ; p>0.05$ vs control).

The effects of APDC to inhibit excitatory synaptic transmission were tested in 21 neurons; in 17 of those neurons $(81 \%)$, APDC induced a concentration-dependent inhibition in amplitude of evoked EPSCs (eEPSCs). The maximum inhibition was induced by $300 \mu \mathrm{M}$ APDC, which decreased eEPSC amplitude from $264 \pm 69.3 \mathrm{pA}$ to $144 \pm 67.6 \mathrm{pA}$, a $51 \pm 11.0 \%$ decrease $(p<0.05 ; n=4)$. The $\mathrm{EC}_{50}$ for the APDC-induced inhibition in eEPSC amplitude was $\sim 20 \mu \mathrm{M}$ (Fig. 1). To determine whether the APDC-induced inhibition in excitatory synaptic transmission occurred via actions at presynaptic receptors, pairs of synaptic currents were evoked (35-50 ms apart) to examine alterations in the paired-pulse ratio (the amplitude of the second current rela- tive to that of the first); alteration in the paired-pulse ratio is indicative of a presynaptic site of action (Travagli et al., 1995; Browning et al., 2006). In six neurons in which APDC (100 $\mu \mathrm{M})$ decreased the amplitude of eEPSCs, the inhibition was accompanied by an increase in the paired-pulse ratio from $0.91 \pm 0.03$ to $1.12 \pm 0.16(p<0.05)$ (data not shown).

As additional confirmation of a presynaptic site of action, the effects of APDC $(100 \mu \mathrm{M})$ were tested on miniature EPSCs (mEPSCs). APDC decreased the frequency $(2.5 \pm 0.8$ to $1.1 \pm 0.2$ events $\left./ \mathrm{s}^{-1} ; n=6 ; p<0.05\right)$ but not the amplitude $(30 \pm 1.9$ to $32 \pm 1.8 ; n=6 ; p>0.05$ ) of mEPSCs (data not shown).

These data indicate that the presence of group II mGluRs on the presynaptic terminals decreases the release of glutamate in gastric vagal brainstem circuits. These data also suggest, however, that group II mGluRs may be present postsynaptically on a small subpopulation of DMV neurons, because the outward shift induced by the agonist APDC was unaffected by the blockade of action potential dependent synaptic transmission with TTX, implying a direct action on the DMV neuronal membrane.

\section{Activation of presynaptic group II mGluRs inhibit inhibitory} synaptic transmission to gastric-projecting DMV neurons The effects of APDC to decrease inhibitory synaptic transmission were examined in 14 neurons in the presence of the nonselective ionotropic glutamate receptor antagonist kynurenic acid ( $1 \mathrm{mM}$; note that kynurenic acid has been shown to also block nicotinic cholinergic receptors (Hilmas et al., 2001; Grilli et al., 2006); however, nAChR do not appear to be tonically active in the NTSDMV synapse (Bertolino et al., 1997a; Sahibzada et al., 2002). In nine of these neurons $(64 \%)$, APDC $(100 \mu \mathrm{M})$ induced a $31 \pm 4.2$ pA outward current $(p>0.05$ vs outward current induced in the presence of picrotoxin). In the presence of $1 \mu \mathrm{M}$ TTX, the outward current induced by APDC was decreased, but not abolished, to $16 \pm 5.8 \mathrm{pA}$ ( $n=3$ of 6 neurons tested; $p>0.05$ vs proportion of neurons responding under control conditions).

In 13 neurons (i.e., 93\%), APDC induced a concentrationdependent inhibition in amplitude of evoked IPSCs (eIPSCs). The maximum inhibition was induced by $300 \mu \mathrm{M}$ APDC, which decreased eIPSC amplitude from $191 \pm 26.2 \mathrm{pA}$ to $136 \pm 19.5 \mathrm{pA}$ (i.e., a $29 \pm 4.3 \%$ decrease; $p<0.05$ vs control; $p<0.05$ compared with the $51 \pm 11 \%$ inhibition in eEPSC amplitude). The $\mathrm{EC}_{50}$ value for the APDC-induced inhibition in eIPSC amplitude was $\sim 20 \mu \mathrm{M}$ (Fig. 1).

To determine whether the APDC-induced inhibition occurred via actions at presynaptic receptors, the ability of APDC $(100 \mu \mathrm{M})$ to alter the paired-pulse ratio of eIPSC amplitude was examined; the APDC-induced inhibition was accompanied by an increase in the paired-pulse ratio from $0.72 \pm 0.07$ to $0.78 \pm 0.08$ $(p<0.05 ; n=6)$ (data not shown), suggesting a presynaptic site of action.

As additional confirmation of a presynaptic location of these receptors, the effects of APDC $(100 \mu \mathrm{M})$ on miniature IPSCs (mIPSCs) was examined in an additional seven neurons. APDC decreased the frequency $\left(1.4 \pm 0.1\right.$ to $0.6 \pm 0.1$ events $^{-1} \mathrm{~s}^{-1} ; n=7$; $p<0.05)$, but not the amplitude $(60 \pm 5.2$ to $63 \pm 5.4 \mathrm{pA} ; n=7$; $p>0.05$ ) of mIPSCs, confirming their presynaptic location (Fig. 2).

It would appear, then, that group II mGluRs are present also on inhibitory gastrointestinal vagal circuits and act to decrease GABAergic synaptic transmission. These data also confirm the results reported above suggesting that group II mGluRs may also be present postsynaptically, because APDC was still able to in- 
duce an outward current, even in the presence of action potential mediated synaptic blockade.

Tonic activation of group II mGluRs in inhibitory, but not excitatory

\section{NTS-DMV synapses}

The effects of the group II mGluR antagonist EGLU $(200 \mu \mathrm{M})$ were tested in 25 gastric-projecting DMV neurons. In no instance was any effect on the postsynaptic DMV membrane observed.

The effects of EGLU on excitatory synaptic transmission were assessed in seven of these neurons; EGLU did not alter the amplitude of eEPSCs in any neuron $(202 \pm 28.9 \mathrm{pA}$ in control vs $196 \pm 28.8 \mathrm{pA}$ in the presence of EGLU; $p>0.05$ ) (Fig. 3 ), and did not alter the paired-pulse ratio $(0.88 \pm 0.13$ in control vs $0.96 \pm 0.14$ in the presence of EGLU; $p>0.05)$. These data would suggest, therefore, that the group II mGluRs present on excitatory glutamatergic gastric vagal brainstem circuits are not activated tonically.

In contrast, in 18 neurons in which the effects of EGLU on inhibitory synaptic transmission were assessed, EGLU increased eIPSC amplitude in 10 neurons (i.e., $56 \%$ ) from $187 \pm 12.4 \mathrm{pA}$ in control to $237 \pm 15.6 \mathrm{pA}$ in the presence of EGLU (i.e., a $27 \pm 4.4 \%$ increase; $p<0.05$ ) (Fig. 3 ) and increased the paired-pulse ratio from $0.69 \pm 0.08$ in control to $0.88 \pm 0.13$ in the presence of EGLU $(p<0.05)$. Furthermore, in an additional six neurons, EGLU increased the frequency $(1.5 \pm 0.8$ to $3.4 \pm 1.1$ events $\left./ \mathrm{s}^{-1} ; p<0.05\right)$, but not the amplitude $(73 \pm 9.0$ to $74 \pm 9.9 \mathrm{pA}$; $p>0.05$ ) of mIPSCs (Fig. 4). These data indicate that group II mGluRs present presynaptically on inhibitory GABAergic gastric vagal brainstem circuits are activated tonically.

Role of vagal afferent nerve terminals in activation of group II mGluRs on excitatory NTS-DMV synapses

To investigate whether vagal afferent fibers play a role in the tonic activation of group II mGluRs on GABAergic synapses, electrophysiological recordings were made from 61 neurons from deafferented rats (i.e., rats in which the vagal afferent nerve rootlets had been removed surgically before experimentation) and recordings were made from DMV neurons ipsilateral to the lesion. For the purposes of comparison, recordings were always made also from the contralateral (vagally intact) DMV, the results of which were not found to vary from those of control rats.

The effects of the group II mGluR agonist APDC were tested in 35 DMV neurons from deafferented rats. In 19 neurons (i.e., $54 \% ; p>0.05$ vs vagally intact rats), in the presence of picrotoxin, $\operatorname{APDC}(100 \mu \mathrm{M})$ induced a $63 \pm 11.6 \mathrm{pA}$ outward shift $(p<0.05$ vs shift induced in vagally intact rats). In contrast to vagally intact rats, however, the magnitude of the APDC-induced outward current was reduced significantly in the presence of TTX $(1 \mu \mathrm{M} ; 38 \pm$
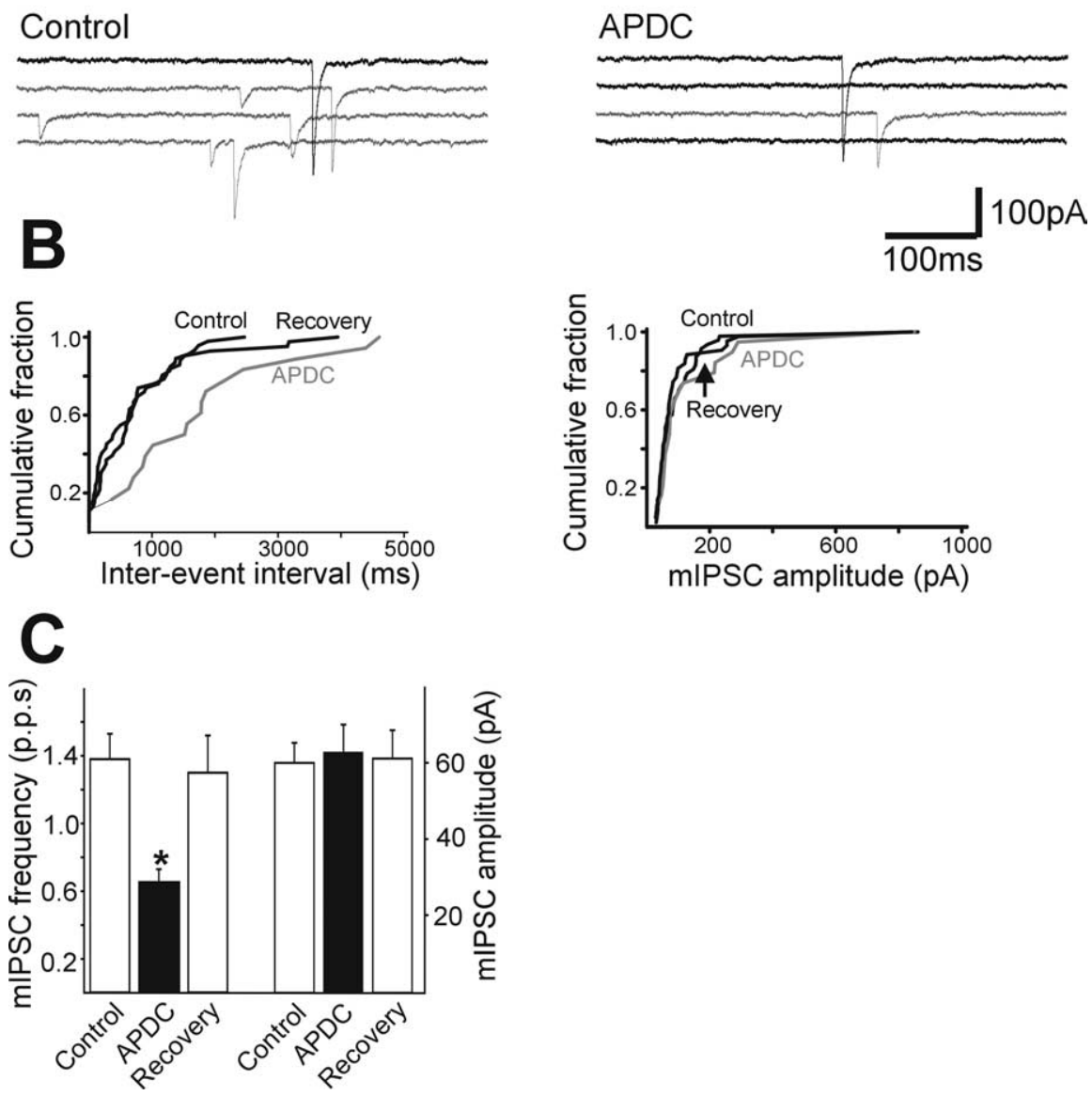

Figure 2. The group II mGluR agonist acts presynaptically to inhibit mIPSC frequency but not amplitude. $\boldsymbol{A}$, Representative traces from a gastric-projecting DMV neuron voltage clamped at $-50 \mathrm{mV}$ showing miniature IPSCs in control conditions (left).

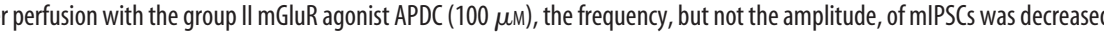
decrease in mIPSC frequency (left), but not amplitude (right). C, Summary of the APDC-induced decrease in mIPSC frequency (left; $\left.{ }^{*} p<0.05\right)$, but not amplitude (right).
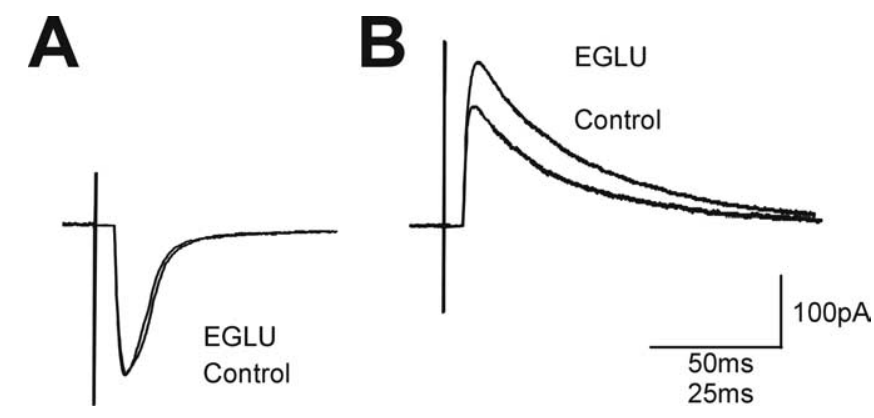

Figure 3. The group II mGluR antagonist EGLU increases the amplitude of evoked IPSCs, but not evoked EPSCS. $\boldsymbol{A}$, Representative trace from a gastric-projecting DMV neuron (voltage clamped at $-60 \mathrm{mV}$ ) in which EPS(s were evoked by electrical stimulation of the adjacent NTS. The amplitude of eEPSCs were unchanged by perfusion with the group II mGluR antagonist EGLU $(200 \mu \mathrm{m})$. Calibration: $25 \mathrm{~ms}, 100$ pA. $\boldsymbol{B}$, Representative trace from a gastric-projecting DMV neuron (voltage clamped at $-50 \mathrm{mV}$ ) in which IPSC s were evoked by electrical stimulation of the adjacent NTS. The amplitude of the eIPSC was increased after perfusion with the group II mGluR antagonist EGLU (200 $\mu \mathrm{m})$. Calibration: 50 ms, 100 pA. 
A

\section{Control}

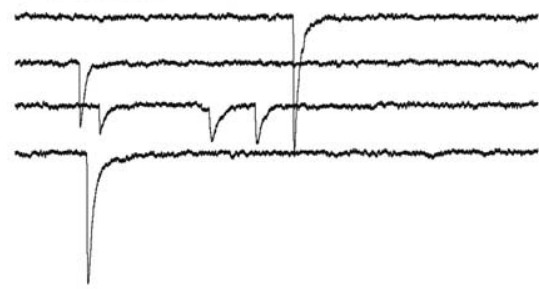

B

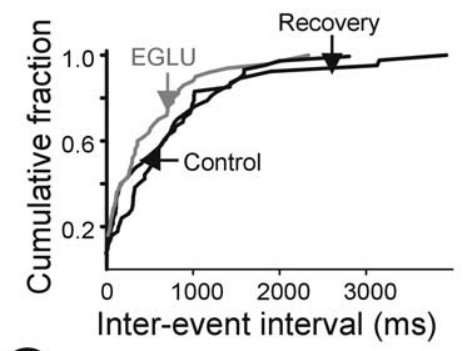

C

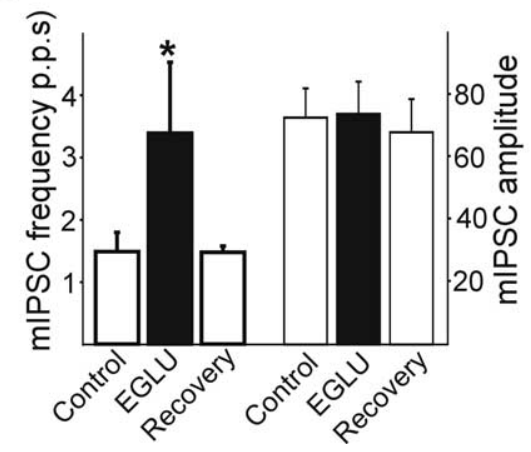

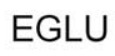
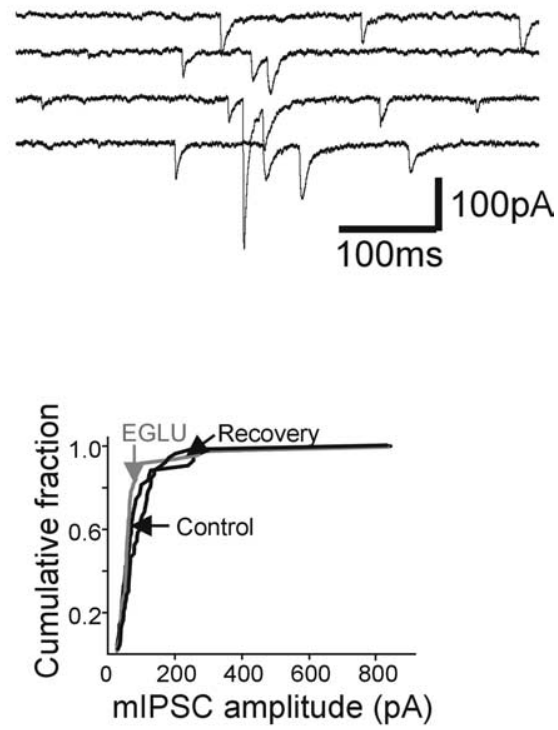

Figure 4. The group II mGluR antagonist EGLU increases the frequency, but not the amplitude, of mIPSCs. $\boldsymbol{A}$, Representative traces from a gastric-projecting DMV neuron voltage clamped at $-50 \mathrm{mV}$ showing mIPSCs in control conditions (left). After perfusion with the group II mGluR antagonist EGLU $(200 \mu \mathrm{m})$, the frequency, but not the amplitude, of mIPSCs was increased (right). Calibration: 100 ms, 100 pA. $\boldsymbol{B}$, Computer-generated graphics from the same neuron as in $\boldsymbol{A}$ showing the EGLU-induced increase in mIPSC frequency (left), but not amplitude (right). C, Summary of the EGLU-induced increase in mIPSC frequency (left; $\left.{ }^{*} p<0.05\right)$, but not amplitude (right).
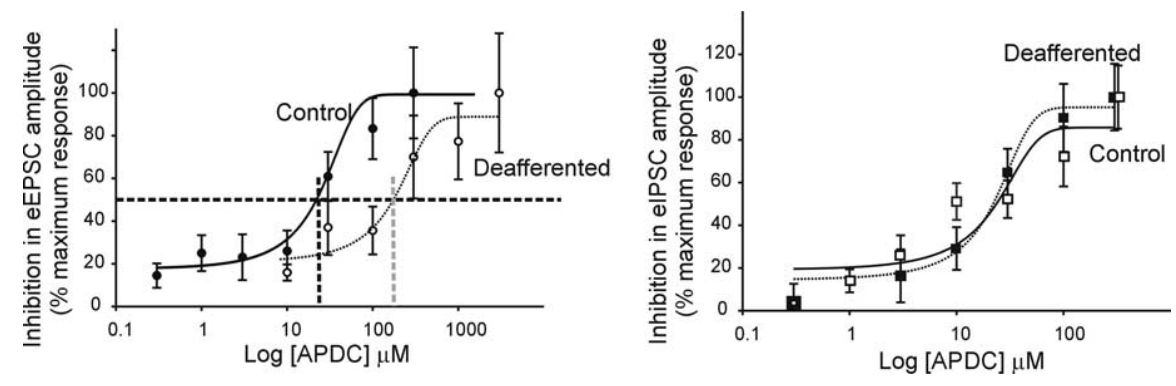

Figure 5. Vagal rootlet deafferentation decreases the ability of the group II mGluR agonist APDC to inhibit excitatory, but not inhibitory, synaptic transmission. After vagal rootlet deafferentation, the log concentration-response curve for the APDC-induced inhibition in eEPSC amplitude was shifted to the right (left graph). The $\mathrm{EC}_{50}$ for the APDC-induced inhibition in eEPSC amplitude in control conditions was $\sim 2 \mu \mathrm{M}$, compared with $\sim 20 \mu \mathrm{m}$ after deafferentation. In contrast, vagal rootlet deafferentation had no effect on the ability of the group II mGluR agonist APDC to inhibit eIPSC amplitude.

$7.9 \mathrm{pA}, p<0.05$ vs current in the absence of TTX; $p>0.05$ vs vagally intact rats).

The effects of APDC to alter excitatory synaptic transmission were tested in 16 neurons. In 13 of these neurons $(81 \% ; p>0.05$ vs vagally intact rats), APDC induced a concentration-dependent inhibition in amplitude of evoked EPSCs. The maximum inhibition was induced by $3000 \mu \mathrm{M}$ APDC, which decreased eEPSC amplitude from $314 \pm 132$ to $201 \pm 123 \mathrm{pA}$ [i.e., $26 \pm$ $10.2 \%$ inhibition; $p<0.05$ vs APDCinduced inhibition in eEPSC amplitude (51 $\pm 11.0 \%$; see above) in vagally intact rats]. The $\mathrm{EC}_{50}$ for the $\mathrm{APDC}$-induced inhibition in eEPSC amplitude was $\sim 200$ $\mu \mathrm{M}$ (Fig. 5).

These group II mGluRs are located at presynaptic sites, because the maximum inhibition in excitatory synaptic transmission by APDC (at $3000 \mu \mathrm{M}$ ) was accompanied by an increase in the paired pulse ratio from $0.79 \pm 0.06$ to $0.90 \pm 0.06(p<$ $0.05 ; n=3)$. Similarly, APDC decreased the frequency $(3.4 \pm 1.3$ to $1.9 \pm 0.7$ events/s $\left.{ }^{-1} ; p<0.05 ; n=6\right)$, but not amplitude ( $36 \pm 2.4$ to $39 \pm 4.4 \mathrm{pA} ; p>0.05$; $n=6)$ of mEPSCs. Because the concentration-response curve to the APDCinduced inhibition was shifted rightwards after vagal deafferentation, these results suggest that group II mGluRs are present on extrinsic (vagal afferent sensory) nerve terminals as well as intrinsic glutamatergic nerve terminals.

Role of vagal afferent nerve terminals in the activation of group II mGluRs on inhibitory NTS-DMV synapses

The effects of APDC to inhibit GABAergic inhibitory synaptic transmission were assessed in 19 neurons from deafferented rats. In six of these neurons $(32 \% ; p>0.05$ vs vagally intact rats), APDC $(100 \mu \mathrm{M})$ induced a $62 \pm 25.4 \mathrm{pA}$ outward shift in the presence of kynurenic acid ( $1 \mathrm{~mm}$; $p<$ 0.05 vs vagally intact rats). In the presence of TTX $(1 \mu \mathrm{M})$, the APDC-induced outward current was reduced to $36 \pm 7.5 \mathrm{pA}$ ( $p<0.05$ vs vagally intact rats; $n=3$ of 6 neurons tested).

Group II mGluRs are still present after vagal deafferentation, because APDC induced a concentration-dependent inhibition in amplitude of eIPSCs in 15 neurons (79\%; $p>0.05$ vs vagally intact rats). The maximum inhibition was induced by 300 $\mu \mathrm{M}$ APDC, which reduced eIPSC amplitude from $239 \pm 78 \mathrm{pA}$ in control to $122 \pm$ $30 \mathrm{pA}$ in the presence of APDC (i.e., $44 \pm$ $6.9 \%$ inhibition; $p<0.05$ vs inhibition induced by APDC in vagally intact rats). The $\mathrm{EC}_{50}$ for the APDC-induced inhibition was $\sim 20 \mu \mathrm{M}$ (Fig. 5).

Group II mGluRs are still present presynaptically, although, because the APDC-induced inhibition in eIPSC amplitude (at $300 \mu \mathrm{M})$ was accompanied by an increase in the paired-pulse ratio from $0.72 \pm 0.09$ to $0.94 \pm 0.16(p<0.05 ; n=4)$. As 
further corroboration of their presynaptic location, APDC decreased the frequency $\left(3.8 \pm 2.2\right.$ to $1.6 \pm 0.8$ events $/ \mathrm{s}^{-1} ; p<$ 0.05 ), but not amplitude ( $70 \pm 10.0$ to $79 \pm 15.9 \mathrm{pA} ; p>0.05)$ of mIPSCs in an additional five neurons from deafferented rats (data not shown). These data show that group II mGluRs are still present on inhibitory brainstem circuits after vagal deafferentation implying that they are not located exclusively on vagal afferent nerve terminals.

The effects of the group II mGluR antagonist EGLU $(200 \mu \mathrm{M})$ on eIPSCs were tested in six gastric-projecting DMV neurons from deafferented rats. In contrast to recordings from vagally intact rats, EGLU had no effect on eIPSC amplitude in deafferented rats $(154 \pm 19 \mathrm{pA}$ in control vs $148 \pm 16 \mathrm{pA}$ in the presence of EGLU; $p>0.05)$. Furthermore, EGLU $(200 \mu \mathrm{M})$ had no effect on either the frequency $\left(1.96 \pm 0.69\right.$ vs $2.14 \pm 1.01$ events $/ \mathrm{s}^{-1}$; $p>0.05 ; n=5)$ or amplitude ( $71 \pm 6.2$ vs $70 \pm 7.7 \mathrm{pA} ; p>0.05$; $n=5)$ of mIPSCs after vagal deafferentation. Thus, these results imply that the tonic activation of group II mGluRs on GABAergic nerve terminals arises from vagal afferent inputs, because deafferentation abolished the effects of the antagonist to increase eIPSC amplitude.

\section{Activation of group III mGluRs inhibits excitatory, but not inhibitory synaptic transmission to gastric-projecting DMV neurons}

The effects of the group III mGluR agonist L-AP-4 were tested on 14 gastric projecting, vagally intact DMV neurons. L-AP-4 did not induce any effect on the postsynaptic DMV neuronal membrane in any of these neurons.

The effects of L-AP-4 to inhibit excitatory synaptic transmission were tested in 11 neurons; in 10 of those neurons (90\%), L-AP-4 induced a concentration-dependent inhibition in amplitude of eEPSCs. The maximum inhibition was induced by $100 \mu \mathrm{M} \mathrm{L}-\mathrm{AP}-4$, which decreased eEPSC amplitude from $278 \pm 51$ to $115 \pm 47 \mathrm{pA}$, a $45 \pm 15.0 \%$ decrease $(p<0.05)$. The $\mathrm{EC}_{50}$ for the L-AP-4-induced inhibition in eEPSC amplitude was $\sim 2 \mu \mathrm{M}$ (Fig. 6).

To investigate whether group III mGluRs were located at presynaptic sites, the effects of L-AP-4 to alter the paired pulse ratio were examined. The maximum inhibition in eEPSC amplitude induced by $300 \mu \mathrm{M} \mathrm{L}-\mathrm{AP}-4$ was accompanied by an increase in the paired pulse ratio from $0.85 \pm 0.14$ to $1.03 \pm 0.08(p<0.05 ; n=$ $4)$, suggesting a presynaptic site of action of the group III mGluR agonist.

Additional confirmation of the presynaptic site of the group III mGluRs was obtained from eight neurons in which the effects of L-AP-4 were tested on mEPSCs. L-AP-4 decreased the frequency ( $3.31 \pm 0.70$ to $1.39 \pm 0.27$ events $\left./ \mathrm{s}^{-1} ; p<0.05\right)$, but not the amplitude $(32.06 \pm 1.04$ to $30.06 \pm 0.70 \mathrm{pA} ; p>0.05)$ of mEPSCs (data not shown). These data suggest that group III mGluRs inhibit glutamatergic excitatory synaptic transmission via actions at presynaptic receptors.

In contrast, L-AP- 4 had no effect on the amplitude of eIPSCs in any neuron tested $(228 \pm 42$ and $226 \pm 34 \mathrm{pA}$ in control and in the presence of L-AP- $4 ; p>0.05, n=4)$ (Fig. 6). Furthermore, L-AP-4 had no effect on mIPSC amplitude $(67 \pm 7.2$ to $63 \pm 6.4$ $\mathrm{pA} ; p>0.05)$ or frequency $\left(2.1 \pm 0.3\right.$ to $1.9 \pm 0.3$ events $/ \mathrm{s}^{-1} ; p>$ 0.05 ) (data not shown) in an additional five neurons. These data suggest that group III mGluRs are not present within inhibitory GABAergic vagal brainstem circuits and play no role in the modulation of GABAergic synaptic transmission under control conditions.
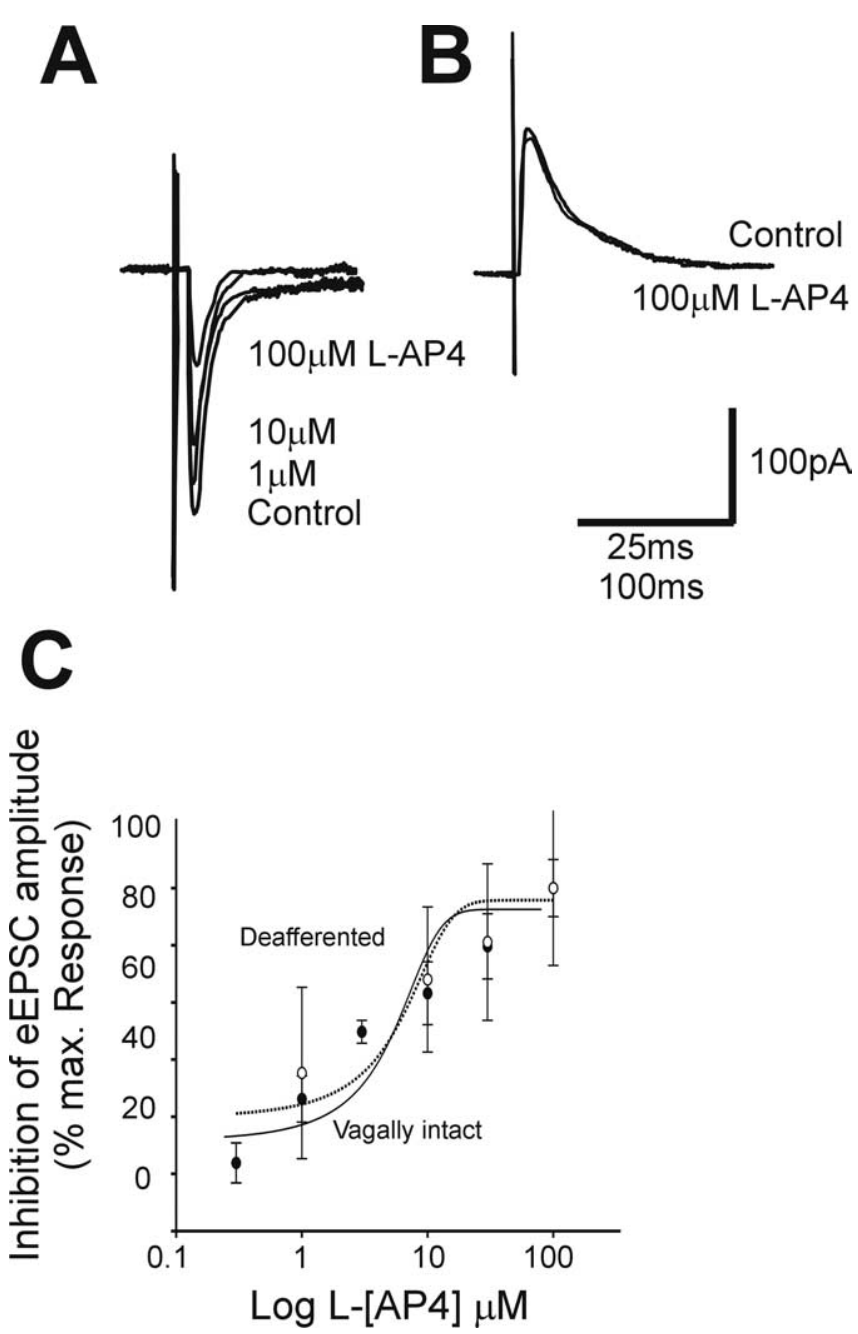

Figure 6. The group III mGluR agonist inhibits excitatory, but not inhibitory, synaptic transmission to gastric-projecting DMV neurons. $\boldsymbol{A}$, In a gastric-projecting DMV neuron voltage clamped at $-60 \mathrm{mV}$, eEPSCs were evoked by electrical stimulation of the adjacent NTS. The group III mGluR agonist L-AP-4 decreased eEPSC amplitude in a concentration-dependent manner. Calibration: $25 \mathrm{~ms}, 100 \mathrm{pA}$. B, In a gastric-projecting DMV neuron voltage clamped at -50 $\mathrm{mV}$, IPSCs were evoked by electrical stimulation of the adjacent NTS. The group III mGluR agonist L-AP-4 had no effect on elPSC amplitude. Calibration: 100 ms, 100 pA. C, Log concentration-response curve for the L-AP-4-induced inhibition in eEPSC amplitude in both control conditions (solid line) and after vagal deafferentation (dashed line). Note that deafferentation had no effect on the efficacy of the L-AP-4-induced inhibition in eEPSC amplitude.

\section{Group III mGluRs in NTS-DMV synapses are not activated tonically}

The effects of the group III mGluR antagonist MSOP $(500 \mu \mathrm{M})$ to modulate excitatory synaptic transmission were tested in 12 neurons. MSOP was never observed to alter the amplitude of evoked EPSCs $(301 \pm 98$ vs $309 \pm 107 \mathrm{pA} ; p>0.05 ; n=5$ ) (data not shown) and had no effect on either mEPSC amplitude $(32 \pm 1.6$ to $31 \pm 1.2 \mathrm{pA} ; n=7 ; p>0.05)$ or frequency $(3.5 \pm 0.7$ to $3.4 \pm$ 0.7 events $/ \mathrm{s}^{-1} ; n=7 ; p>0.05$ ) (data not shown). These data indicate that group III mGluRs on excitatory gastric brainstem circuits are not activated tonically.

The effects of MSOP $(500 \mu \mathrm{M})$ to modulate inhibitory synaptic transmission were tested in an additional nine neurons. MSOP was never observed to exert any effect on eIPSC (223 \pm 51 vs $221 \pm 52 \mathrm{pA} ; p>0.05 ; n=4$ ) (data not shown) or on mIPSC amplitude $(67 \pm 7.2$ to $63 \pm 6.4 \mathrm{pA} ; p>0.05 ; n=5)$ or frequency 

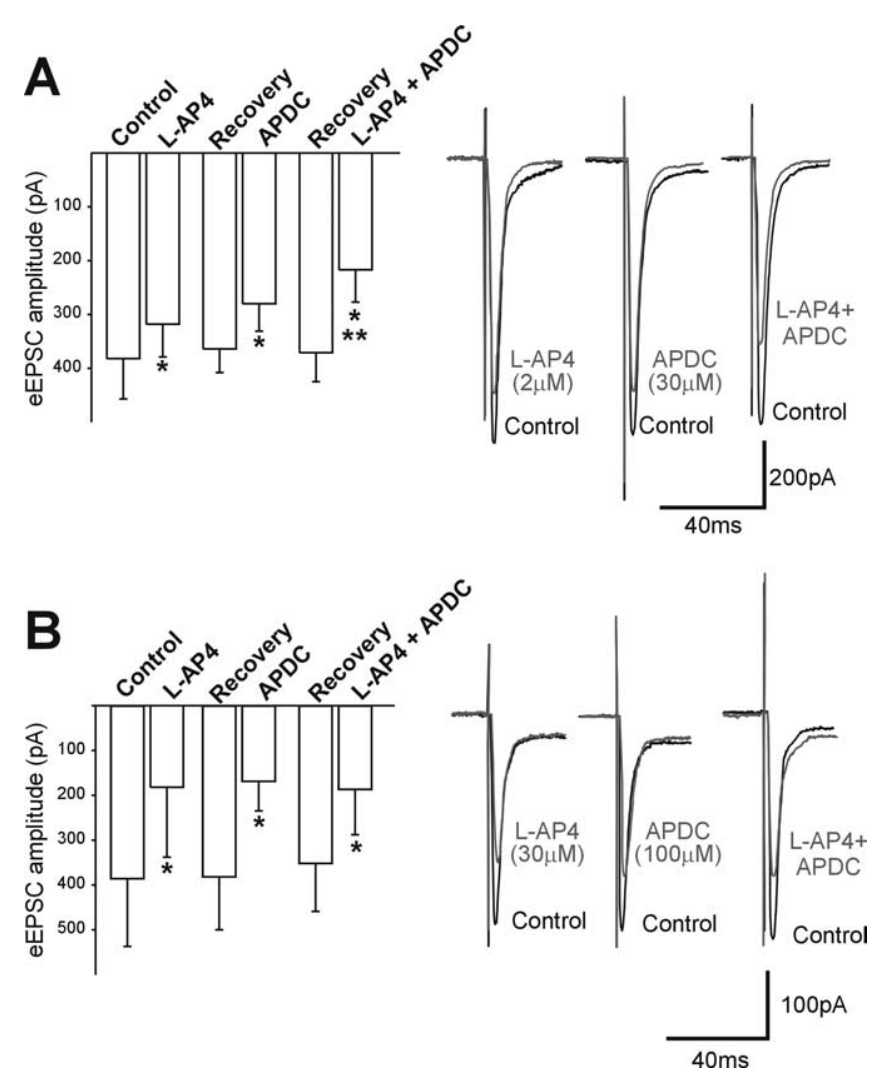

Figure 7. Groups II and III mGluR agonists inhibit excitatory synaptic transmission to gastricprojecting DMV neurons in an additive manner. $\boldsymbol{A}$, Histogram (left) and representative traces (right) summarizing the additive effects of submaximal concentrations of the groups II and III mGluR agonists APDC and L-AP-4, respectively, to inhibit excitatory synaptic transmission to gastric-projecting DMV neurons, voltage clamped at $-60 \mathrm{mV}$. B, Histogram (left) and representative traces (right) demonstrating that maximal concentrations of the groups II and III mGluR agonists APDC and L-AP-4, respectively, did not summate to induce a larger inhibition in excitatory synaptic transmission to gastric-projecting DMV neurons. ${ }^{*} p<0.05$ vs control; ${ }^{* *} p<0.05$ vs either agonist alone.

$\left(2.1 \pm 0.3\right.$ to $1.9 \pm 0.3$ events $\left./ \mathrm{s}^{-1} ; p>0.05 ; n=5\right)$ (data not shown).

\section{Excitatory NTS-DMV synapses contain both group II and group III mGluRs}

In an additional seven neurons, the effects of both group II and group III mGluRs were assessed on excitatory synaptic transmission to gastric-projecting DMV neurons. In six of these neurons (86\%), both L-AP-4 and APDC induced an inhibition in eEPSC amplitude; the remaining neuron was unresponsive to both agonists. There was no instance in which eEPSC amplitude was inhibited by one agonist, but not the other.

In four neurons, the effects of perimaximal concentrations of both group II and group III agonists on eEPSC amplitude were tested (APDC, $100 \mu \mathrm{M}$; L-AP-4, 30-100 $\mu \mathrm{M}$, respectively). The group III agonist inhibited eEPSC amplitude by $36 \pm 10.9 \%$ (from $386 \pm 152$ to $282 \pm 156 \mathrm{pA} ; p<0.05$ ) whereas the group II agonist inhibited eEPSC amplitude by $57 \pm 6.4 \%$ (from $382 \pm$ 118 to $169 \pm 66 \mathrm{pA} ; p<0.05)$. The inhibition in eEPSC amplitude induced by a combination of both agonists, however, was $54 \pm 13.5 \%$ (from $353 \pm 107$ to $187 \pm 101 \mathrm{pA} ; p<0.05 ; p>0.05$ vs inhibition by group II agonist alone) (Fig. 7) (i.e., coapplication of perimaximal concentrations of both group II and group III mGluR agonists were not additive).

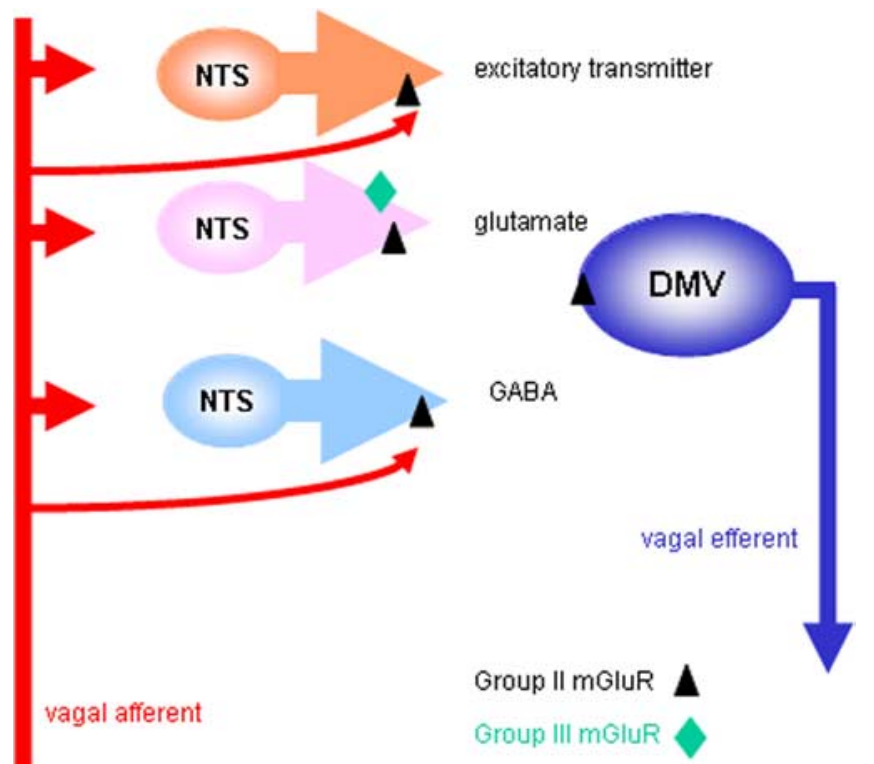

Figure 8. Proposed schematic representation of the location of groups II and III mGluRs within gastric vagal brainstem circuits. This scheme illustrates the presynaptic location of group II mGluRs on GABAergic, glutamatergic, and other excitatory nerve terminals impinging on gastric-projecting DMV neurons within the rat brainstem. Group III mGluRs were also identified on glutamatergic nerve terminals, whereas group II mGluRs were present on the postsynaptic membrane of some DMV neurons. GABAergic, but not glutamatergic nerve terminals appear to receive a tonically active monosynaptic glutamatergic input from vagal afferent nerve terminals. Our results further suggest that nonglutamatergic excitatory nerve terminals receive a similar tonic vagal afferent glutamatergic input.

In another four neurons, the effects of submaximal concentrations of both group II and group III agonists on eEPSC amplitude were tested (APDC, $20 \mu \mathrm{M}$; L-AP-4, $2 \mu \mathrm{M}$, respectively). The group III agonist inhibited eEPSC amplitude by $17 \pm 1.8 \%$ (from $382 \pm 75$ to $318 \pm 61 \mathrm{pA} ; p<0.05)$ whereas the group II agonist inhibited eEPSC amplitude by $24 \pm 5.4 \%$ (from $363 \pm 44$ to $280 \pm 51 \mathrm{pA} ; p<0.05)$. The inhibition induced by a combination of both agonists, however, was $44 \pm 7.1 \%$ (from $371 \pm 54$ to $217 \pm 60 \mathrm{pA} ; p<0.05 ; p<0.05$ vs inhibition induced by either agonist alone) (Fig. 7) (i.e., coapplication of submaximal concentrations of both group II and group III mGluR agonists inhibited eEPSC amplitude in an additive manner). These results suggest that excitatory glutamatergic nerve terminals within gastric vagal brainstem circuits contain both group II and group III mGluRs, and that these two receptor classes may, indeed, share a common mechanistic pathway.

\section{Discussion}

In this study we have shown that (1) group II mGluRs are present on excitatory and inhibitory neuronal terminals in the DVC (i.e., NTS, DMV, and area postrema), (2) group II mGluRs on inhibitory synapses are activated tonically, and (3) group III mGluRs are present on excitatory DVC neuronal terminals only, but not activated tonically. Our data indicate that group II and III mGluRs are distributed differently on DVC nerve terminals and that profound differences exist in the monosynaptic connections of vagal afferent neurons within homeostatic brainstem circuits (Fig. 8). Because of this, it is possible that group II mGluRs have different physiological roles from group III mGluRs within homeostatic brainstem vagal circuits. 


\section{Organization and role of group II mGluRs within GABAergic} gastric vagal brainstem circuits

The present study confirms and extends our previous findings that inhibitory GABAergic nerve terminals innervating gastricprojecting DMV neurons receive an apparent monosynaptic glutamatergic input from vagal afferent neurons (Browning et al., 2006). Glutamate released from these sensory vagal terminals activates group II mGluRs on GABAergic terminals attenuating inhibitory synaptic transmission to DMV neurons. This vagal glutamatergic input appears to be tonically active, because removal of vagal afferents, via surgical rootlet rhizotomy, abolished the ability of the selective group II mGluR antagonist to increase GABAergic synaptic transmission. Furthermore, the group II mGluR agonist-induced inhibition of GABAergic synaptic transmission was increased after deafferentation, which may reflect a loss of receptor occupancy; the lack of alteration in agonist sensitivity suggests that removal of the tonic glutamatergic input did not upregulate presynaptic group II mGluRs.

\section{Organization and role of group II mGluRs within glutamatergic gastric vagal brainstem circuits}

The present study also demonstrates that activation of presynaptic group II mGluRs within the DVC inhibits glutamatergic synaptic transmission to DMV neurons. In contrast to inhibitory terminals, group II mGluRs on presumed glutamatergic nerve terminals were not activated tonically, because receptor antagonism did not affect excitatory synaptic transmission. After vagal deafferentation, the ability of the agonist to inhibit glutamatergic synaptic transmission was reduced, but not abolished, suggesting that group II mGluRs are not present exclusively on intrinsic nerve terminals, but are also present on extrinsic (vagal afferent sensory) nerve terminals, and that the electrical stimulation parameters used in the present study stimulate glutamate release from these extrinsic nerve fibers. Vagal deafferentation also decreased the absolute magnitude of the agonist-induced inhibition and reduced the agonist efficacy, implying that group II mGluRs present on vagal afferent (extrinsic) nerve terminals may function as autoreceptors.

Although the present study suggests that glutamatergic and GABAergic brainstem vagal neuronal terminals contain group II mGluRs, there is little evidence to suggest they play a prominent role in NTS neuronal excitability. A previous study proposed a postsynaptic site of action on NTS neurons, but the mGluR agonist used was equiactive at both group I and II mGluRs (Glaum and Miller, 1993a). Indeed, more recent work using selective group II mGluR agonists failed to report any postsynaptic actions on NTS neurons (Chen et al., 2002; Jin et al., 2004). In the present study, application of the group II mGluR agonist induced an outward current in $\sim 60 \%$ of DMV neurons. This outward current was unaffected by TTX (to block action potential dependent synaptic transmission), suggesting that group II mGluRs are also located on the membrane of a subpopulation of DMV neurons. After vagal deafferentation, however, the magnitude of this outward current was increased significantly, and this increased response was attenuated by TTX. This may imply that deafferentation increases nonglutamatergic excitatory transmission onto DMV neurons; exogenous application of the group II mGluR agonist acts presynaptically to attenuate this increased neurotransmission, with the observed result being an outward, TTXsensitive current on the postsynaptic DMV neuronal membrane. This also suggests that nonglutamatergic, possibly catecholaminergic (Rogers et al., 2003), excitatory release sites receive monosynaptic (extrinsic) vagal afferent inputs. Removal of this input relieves the tonic activation of presynaptic group II mGluRs and, hence, increases their synaptic transmission (Fig. 8).

\section{Organization and role of group III mGluRs within excitatory gastric vagal brainstem circuits}

The present study demonstrates that group III mGluRs are present on excitatory nerve terminals within the DVC and inhibit glutamatergic synaptic transmission to DMV neurons. As with group II mGluRs on glutamatergic nerve terminals, these receptors were not activated tonically because the antagonist was ineffective.

The group III mGluR agonist still inhibited excitatory synaptic transmission after vagal deafferentation, suggesting that these receptors are present on intrinsic glutamatergic nerve terminals. Indeed, deafferentation altered neither the maximal inhibition in eEPSC amplitude nor the agonist $\mathrm{EC}_{50}$, suggesting either that group III mGluRs are not present on extrinsic (vagal afferent) glutamatergic nerve terminals or, if they are present, that they do not play a significant role in the modulation of glutamatergic transmission to DMV neurons.

It is of interest to note that, although activation of group II and III mGluRs appears to inhibit excitatory synaptic transmission to a similar degree, the potency of the endogenous agonist (glutamate) differs at groups II and III mGluR subtypes (Conn and Pin, 1997; Cartmell and Schoepp, 2000). In future studies, we will address the functionally relevant role, if any, of these differences within brainstem vagal circuits.

In contrast, under control conditions, group III mGluRs were never found on GABAergic nerve terminals within gastric brainstem vagal circuits. Neither the agonist nor the antagonist altered inhibitory GABAergic synaptic transmission, eliminating the possibility that group III mGluRs were present on GABAergic nerve terminals, but were maximally activated by a tonic vagal afferent input.

\section{Different functional roles of group II and group III mGluRs within gastric vagal brainstem circuits}

The electrical stimulation parameters used in these experiments are certain to activate multiple synaptic inputs. Consequently, it is difficult to determine whether any single glutamatergic nerve terminal contains discrete populations of either group II or group III mGluRs, or whether any single nerve terminal contains a mixture of both receptors. Although, when the responses to both agonists were examined, excitatory synaptic transmission was either inhibited by, or was unresponsive to, both agonists (i.e., there was no instance where excitatory synaptic transmission was inhibited by either group II or group III mGluR agonists only). Furthermore, submaximal concentrations of group II and group III mGluR agonists were additive suggesting that glutamatergic nerve terminals contain a mixed population of receptors that do, indeed, share a common second messenger pathway (Conn and Pin, 1997; Cartmell and Schoepp, 2000).

\section{Physiological significance}

In the present study, differences were found within the synaptic neural inputs and connections between excitatory and inhibitory brainstem circuits. Inhibitory GABAergic synapses that innervate DMV neurons receive an apparent monosynaptic glutamatergic input from vagal afferent nerve fibers. Glutamate released from these sensory vagal nerve terminals activates presynaptic group II mGluRs to attenuate GABAergic inhibitory synaptic transmission (Browning et al., 2006). Removal of this tonic input, via vagal afferent rootlet rhizotomy, abolished the ability of the se- 
lective group II mGluR antagonist to increase GABAergic neurotransmission. In contrast, although both group II and group III mGluRs were found on excitatory nerve terminals projecting to DMV neurons, they did not receive a tonic vagal glutamatergic input.

Previous studies have suggested that, at least with respect to gastric brainstem circuits, the GABAergic synapse between the NTS and the DMV, rather than the glutamatergic synapse, is of primary importance in regulating parasympathetic outflow to the stomach (Sivarao et al., 1998). At first glance, controlling GABAergic transmission between the NTS and DMV in such a rigorous manner appears somewhat ponderous and burdensome. As we have postulated previously, however, using vagal afferent neurons as the means by which this regulation takes place may provide a convenient means by which sensory input controls the resulting motor output in an "on-demand," but metabolically inexpensive and efficient manner (Browning and Travagli, 2006).

From the present study, one can also infer that the central circuitry of vagal afferent sensory nerve terminals forms discrete and distinct monosynaptic connections with inhibitory, but not excitatory, terminals within gastric vagal brainstem circuits. This provides additional proof for the concept that vago-vagal reflex pathways are organized in well defined circuits (Powley et al., 1992), even at the level of the first central synapse (Bailey et al., 2002) and that, at least anatomically, vagal circuits are pathway specific. The present study has extended these observations to demonstrate that the functional organization of mGluRs within excitatory and inhibitory gastric brainstem vagal circuits, as well as their neuronal pathways and synaptic connections, is different from that of cardiovascular and respiratory brainstem vagal circuits (Chen et al., 2002; Jin et al., 2004; Chen and Bonham, 2005). Such organizational disparities may reflect the functional differences in the timing of cardiovascular and respiratory compared with gastrointestinal vagal reflexes, because the latter do not require regulation and modulation on a millisecond basis to fulfill their physiological role. This type of "slower" regulation, and its apparent role in receptor trafficking (Browning et al., 2006), may have physiological relevance by allowing brainstem circuits to undergo the necessary plastic adaptations to respond to everchanging homeostatic control by higher CNS centers.

\section{References}

Andresen MC, Kunze DL (1994) Nucleus tractus solitarius-gateway to neural circulatory control. Annu Rev Physiol 56:93-116.

Andresen MC, Yang M (1990) Non-NMDA receptors mediate sensory afferent synaptic transmission in medial nucleus tractus solitarius. Am J Physiol 259:H1307-H1311.

Bailey TW, Jin YH, Doyle MW, Andresen MC (2002) Vanilloid-sensitive afferents activate neurons with prominent A-type potassium currents in nucleus tractus solitarius. J Neurosci 22:8230-8237.

Baptista V, Zheng ZL, Coleman FH, Rogers RC, Travagli RA (2005) Characterization of neurons of the nucleus tractus solitarius pars centralis. Brain Res 1052:139-146.

Baptista V, Browning KN, Travagli RA (2007) Effects of cholecystokinin-8s in the nucleus tractus solitarius of vagally deafferented rats. Am J Physiol Regul Integr Comp Physiol 292:R1092-R100.

Berthoud HR (2007) Interactions between the "cognitive" and "metabolic" brain in the control of food intake. Physiol Behav, in press.

Bertolino M, Kellar KJ, Vicini S, Gillis RA (1997a) Nicotinic receptor mediates spontaneous GABA release in the rat dorsal motor nucleus of the vagus. Neuroscience 79:671-681.

Bertolino M, Vicini S, Gillis RA, Travagli RA (1997b) Presynaptic $\alpha_{2}$ adrenoceptors inhibit excitatory synaptic transmission in rat brain stem. Am J Physiol 272:G654-G661.

Browning KN, Travagli RA (2003) Neuropeptide Y and peptide YY inhibit excitatory synaptic transmission in the rat dorsal motor nucleus of the vagus. J Physiol (Lond) 549:775-785.

Browning KN, Travagli RA (2006) Short-term receptor trafficking in the dorsal vagal complex: an overview. Auton Neurosci 126-127:2-8.

Browning KN, Renehan WE, Travagli RA (1999) Electrophysiological and morphological heterogeneity of rat dorsal vagal neurones which project to specific areas of the gastrointestinal tract. J Physiol (Lond) 517:521-532.

Browning KN, Kalyuzhny AE, Travagli RA (2002) Opioid peptides inhibit excitatory but not inhibitory synaptic transmission in the rat dorsal motor nucleus of the vagus. J Neurosci 22:2998-3004.

Browning KN, Kalyuzhny AE, Travagli RA (2004) Mu-opioid receptor trafficking on inhibitory synapses in the rat brainstem. J Neurosci 24:7344-7352.

Browning KN, Zheng Z, Gettys TW, Travagli RA (2006) Vagal afferent control of opioidergic effects in rat brainstem circuits. J Physiol (Lond) 575:761-776.

Cartmell J, Schoepp DD (2000) Regulation of neurotransmitter release by metabotropic glutamate receptors. J Neurochem 75:889-907.

Chen CY, Bonham AC (2005) Glutamate suppresses GABA release via presynaptic metabotropic glutamate receptors at baroreceptor neurones in rats. J Physiol (Lond) 562:535-551.

Chen CY, Ling EH, Horowitz JM, Bonham AC (2002) Synaptic transmission in nucleus tractus solitarius is depressed by group II and III but not group I presynaptic metabotropic glutamate receptors in rats. J Physiol (Lond) 538:773-786.

Conn PJ, Pin JP (1997) Pharmacology and functions of metabotropic glutamate receptors. Annu Rev Pharmacol Toxicol 37:205-237.

Davis SF, Derbenev AV, Williams KW, Glatzer NR, Smith BN (2004) Excitatory and inhibitory local circuit input to the rat dorsal motor nucleus of the vagus originating from the nucleus tractus solitarius. Brain Res 1017:208-217.

Derbenev AV, Stuart TC, Smith BN (2004) Cannabinoids suppress synaptic input to neurones of the rat dorsal motor nucleus of the vagus nerve. J Physiol (Lond) 559:923-938.

Glaum SR, Miller RJ (1993a) Activation of metabotropic glutamate receptors produces reciprocal regulation of ionotropic glutamate and GABA responses in the nucleus of the tractus solitarius of the rat. J Neurosci 13:1636-1641.

Glaum SR, Miller RJ (1993b) Metabotropic glutamate receptors depress afferent excitatory transmission in the rat nucleus tractus solitarii. J Neurophysiol 70:2669-2672.

Grilli M, Raiteri L, Patti L, Parodi M, Robino F, Raiteri M, Marchi M (2006) Modulation of the function of presynaptic $\alpha 7$ and non- $\alpha 7$ nicotinic receptors by the tryptophan metabolites, 5-hydroxyindole and kynurenate in mouse brain. Br J Pharmacol 149:724-732.

Hay M, McKenzie H, Lindsley K, Dietz N, Bradley SR, Conn PJ, Hasser EM (1999) Heterogeneity of metabotropic glutamate receptors in autonomic cell groups of the medulla oblongata of the rat. J Comp Neurol 403:486-501.

Hilmas C, Pereira EF, Alkondon M, Rassoulpour A, Schwarcz R, Albuquerque EX (2001) The brain metabolite kynurenic acid inhibits $\alpha 7$ nicotinic receptor activity and increases non- $\alpha 7$ nicotinic receptor expression: physiopathological implications. J Neurosci 21:7463-7473.

Hoang CJ, Hay M (2001) Expression of metabotropic glutamate receptors in nodose ganglia and the nucleus of the solitary tract. Am J Physiol Heart Circ Physiol 281:H457-H462.

Hornby PJ (2001) Receptors and transmission in the brain-gut axis II. Excitatory amino acids receptors in the brain-gut axis. Am J Physiol 280:G1055-G1060.

Jean A (2001) Brain stem control of swallowing: neuronal network and cellular mechanisms. Physiol Rev 81:929-969.

Jin YH, Bailey TW, Andresen MC (2004) Cranial afferent glutamate heterosynaptically modulates GABA release onto second-order neurons via distinctly segregated metabotropic glutamate receptors. J Neurosci 24:9332-9340.

Pamidimukkala J, Hoang CJ, Hay M (2002) Expression of metabotropic glutamate receptor 8 in autonomic cell groups of the medulla oblongata of the rat. Brain Res 957:162-173.

Powley TL, Berthoud HR, Fox EA, Laughton W (1992) The dorsal vagal complex forms a sensory-motor lattice: the circuitry of gastrointesti- 
nal reflexes. In: Neuroanatomy and physiology of abdominal vagal afferents (Ritter S, Ritter RC, Barnes CD, eds), pp 55-79. Boca Raton, FL: CRC.

Rogers RC, Travagli RA, Hermann GE (2003) Noradrenergic neurons in the rat solitary nucleus participate in the esophageal-gastric relaxation reflex. Am J Physiol Regul Integr Comp Physiol 285:R479-R489.

Sahibzada N, Ferreira Jr M, Williams B, Wasserman A, Vicini S, Gillis RA (2002) Nicotinic ACh receptor subtypes on gastrointestinally projecting neurones in the dorsal motor vagal nucleus of the rat. J Physiol (Lond) 545:1007-1016.

Sivarao DV, Krowicki ZK, Hornby PJ (1998) Role of GABA $A_{A}$ receptors in rat hindbrain nuclei controlling gastric motor function. Neurogastroenterol Motil 10:305-313.
Travagli RA, Gillis RA, Rossiter CD, Vicini S (1991) Glutamate and GABAmediated synaptic currents in neurons of the rat dorsal motor nucleus of the vagus. Am J Physiol 260:G531-G536.

Travagli RA, Dunwiddie TV, Williams JT (1995) Opioid inhibition in locus coeruleus. J Neurophysiol 74:519-528.

Travagli RA, Hermann GE, Browning KN, Rogers RC (2006) Brainstem circuits regulating gastric function. Annu Rev Physiol 68:279-305.

Williams KW, Zsombok A, Smith BN (2006) Rapid inhibition of neurons in the dorsal motor nucleus of the vagus by leptin. Endocrinology 148:1868-1881.

Willis A, Mihalevich M, Neff RA, Mendelowitz D (1996) Three types of postsynaptic glutamatergic receptors are activated in DMNX neurons upon stimulation of NTS. Am J Physiol 271:R1614-R1619. 